\title{
Substitution Effects on the Optoelectronic Properties of Coumarin Derivatives
}

\author{
Amit Kumar ${ }^{1, *(\mathbb{D}}$, Roberto Baccoli ${ }^{2}$, Antonella Fais ${ }^{3}{ }^{\circledR}$, Alberto Cincotti ${ }^{4}{ }^{\oplus}$, Luca Pilia ${ }^{4}(\mathbb{C}$ \\ and Gianluca Gatto 1,*iD \\ 1 Department of Electrical and Electronic Engineering, University of Cagliari, via Marengo 2, \\ 09123 Cagliari, Italy \\ 2 Institute of Technical Physics, University of Cagliari, via Marengo 2, 09123 Cagliari, Italy; rbaccoli@unica.it \\ 3 Department of Life and Environmental Sciences, University of Cagliari, Monserrato, 09042 Cagliari, Italy; \\ fais@unica.it \\ 4 Department of Mechanical, Chemical and Material Engineering, University of Cagliari, via Marengo 2, \\ 09123 Cagliari, Italy; alberto.cincotti@dimcm.unica.it (A.C.); luca.pilia@dimcm.unica.it (L.P.) \\ * Correspondence: amit369@gmail.com or amit.kumar@unica.it (A.K.); gatto@diee.unica.it (G.G.)
}

Received: 26 November 2019; Accepted: 21 December 2019; Published: 23 December 2019

\begin{abstract}
Coumarin derivatives have gathered major attention largely due to their versatile utility in a wide range of applications. In this framework, we report a comparative computational investigation on the optoelectronic properties of 3-phenylcoumarin and 3-heteroarylcoumarin derivatives established as enzyme inhibitors. Specifically, we concentrate on the variation in the optoelectronic characteristics for the hydroxyl group substitutions within the coumarin moiety. In order to realize our aims, all-electron density functional theory and time dependent density functional theory calculations were performed with a localized Gaussian basis-set matched with a hybrid exchange-correlation functionals. Molecular properties such as highest occupied molecular orbital (HOMO) and lowest unoccupied molecular orbital (LUMO) energies, vertical ionization ( $\mathrm{IE}_{\mathrm{V}}$ ) and electron affinity energies, absorption spectra, quasi-particle gap, and exciton binding energy values are examined. Furthermore, the influence of solvent on the optical properties of the molecules is considered. We found a good agreement between the experimental $(8.72 \mathrm{eV})$ and calculated $(8.71 \mathrm{eV})$ $\mathrm{IE}_{\mathrm{V}}$ energy values for coumarin. The computed exciton binding energy of the investigated molecules indicated their potential optoelectronics application.
\end{abstract}

Keywords: coumarin derivatives; electronic and optical properties; density functional theory; optoelectronics application

\section{Introduction}

Coumarin is one of the most versatile and studied scaffolds. It exhibits interesting biological, pharmacological, biochemical, therapeutic, and photochemical properties with a wide range of applications [1-4]. It is classified in the benzopyrone family, and formed by fusion of $\alpha$-pyrone ring with a benzene nucleus. Coumarin was first isolated in 1820 from tonka bean by A. Vogel and has since been reported to be present in seeds, roots, and leaves of many plant species, especially in green plants [5].

Coumarin molecule (2H-chromen-2-one) exerts diversified nature of interactions (hydrophobic, hydrogen bonds, electrostatics) with many key sites in organisms and therefore it is able to display wide-range of pharmacological activities [2,6]. Furthermore, coumarin derivatives are synthesized for different application as dye-sensitized solar cells and dye lasers [7]. Moreover, a multifaceted utility of coumarin is possible thanks to flexible structural variations in the scaffold positions ( 3 and 4 ) 
by substitution on the aromatic ring [8]. Because of their synthetic versatility, phenylcoumarins (an extra phenyl ring is attached to any position of the coumarin scaffold) are considered as important molecular moiety with proved biological and pharmacological properties [9]. Notably, 3-phenylcoumarins (an extra phenyl ring attached to 3-position of the coumarin scaffold) has attracted more attention, since their molecular structure closely resembles combination of two pharmacophores (courmain-resveratol). In these molecules, the 3,4-double bond of the coumarin nucleus fixes the trans disposition of the $t$-resveratrol-type double bond. Trans-resveratrol displays pharmacological activities $[10,11]$ and protective effect against cardiovascular and neurodegenerative diseases [12,13]. On the other hand, replacement of phenyl ring in position 3 with thiophene (a heterocyclic compound) resulted in a 3-heteroarylcoumarin moiety [14], with promising applications in coumarin based dyes [15], florescence microscopy and nanoscopy [16]. A significant number of research studies have investigated the potential of 3-phenylcoumarins [17-20] and 3-heteroarylcoumarins [21-23] derivatives as inhibitors against many target enzymes that are associated to different biological diseases $[18,24]$.

In a recent study [13], authors investigated the inhibitory potential of twenty 3-phenylcoumarin and eight 3-heteroarylcoumarin derivatives against xanthine oxidase enzyme, commonly associated to gout [25]. Computational methods can be employed to provide valuable molecular information for these coumarin derivatives. Therefore, the principal objective of this work was to investigate the structure, electronic and optical properties of these same derivatives (Figure 1), in order to establish the relationship between the chemical substitutions and computed molecular properties to aid in the design of materials with potential optoelectronic applications [26].

Coumarin<smiles>O=c1ccc2ccccc2o1</smiles>

A<smiles>O=c1oc2ccccc2cc1-c1ccccc1</smiles>

B<smiles>O=c1oc2c(O)cccc2cc1-c1ccc(Br)cc1</smiles>

C<smiles>O=c1oc2cc(O)cc(O)c2cc1-c1cccc(O)c1</smiles>

D<smiles>O=c1oc2cc(O)cc(O)c2cc1-c1cccs1</smiles>

Figure 1. Chemical structure of coumarin, 3-phenylcoumarins (A-C), and 3-heteroarylcoumarin derivatives (D) are shown here.

To do so, we employed density functional theory (DFT) [27], by far the most popular quantum mechanical method to calculate the structure and electronic properties of the molecules [28-30]. A detailed computational investigation was performed on the four coumarin-derivatives, which were selected on the basis of their enzyme inhibition capability [13]. Further, to provide a systematic investigation on the optical properties (absorption spectrum, electronic states transitions), time-dependent DFT (TD-DFT) [31] calculations were performed on the optimized ground state structures of the molecules in vacuum. Several computational DFT studies have investigated molecular properties of coumarin derivatives for applications such as optoelectronics [26,32], solar cells [7,33-36], fluorescent dyes and lasers [7,37].

In order to extract useful information about properties that determine the performance of molecules in solution, it is important to understand the role of solvents. Several studies have shown the impact of solvent on the absorption spectral characteristics of the molecules [7,38-40]. Therefore, to understand 
and analyze the impact of solvents on the electronic absorption characteristics of molecules, TD-DFT calculations with same level of description was performed on the representative molecular structure that was extracted from classical molecular dynamics (MD) simulations of the molecules inserted in a water box. Finally, the molecules were evaluated for their relevance in optoelectronic properties.

\section{Computational Method}

\subsection{Molecule Preparation and DFT/TD-DFT Calculations}

First, the two-dimensional (2D) structure of the molecules was drawn using Marvin, and the 2D structure was converted into a three-dimensional (3D), using open babel software [41].

Geometry optimization on the obtained 3D structures of the molecules was performed within the framework of density functional theory (DFT) using Gaussian basis-set 6-31G* [42] in combination with a hybrid exchange-correlation functional, Becke's three-parameter and Lee-Yang-Parr functional (B3LYP) [43-45]. For comparison, all the calculations were repeated with a B3LYP/6-311+G* basis set and Perdew-Burke-Ernzerhof (PBE)/6-31G* basis set.

From the geometry-optimized structure of each molecule the highest occupied molecular orbital $\left(\mathrm{E}_{\mathrm{HOMO}}\right)$ and the lowest unoccupied molecular orbital $\left(\mathrm{E}_{\mathrm{LUMO}}\right)$ values were obtained. Using the $\mathrm{E}_{\mathrm{HOMO}}$ and $\mathrm{E}_{\mathrm{LUMO}}$ values, global reactivity descriptors such as chemical potential $(\mathrm{CP})$ and chemical hardness $(\eta)$ were evaluated using the following Equations [46,47]:

$$
\begin{gathered}
C P=\frac{E_{\text {HOMO }}+E_{\text {LUMO }}}{2} \\
\eta=\frac{E_{H O M O}-E_{L U M O}}{2}
\end{gathered}
$$

The vertical ionization energies $\left(\mathrm{IE}_{\mathrm{V}}\right)$ and electron affinity $\left(\mathrm{EA}_{\mathrm{V}}\right)$ were computed using the DFT total energy difference considering the neutral and charged $( \pm 1)$ species $[48,49]$ :

$$
\begin{aligned}
& I E_{V}=E_{\text {cation }}^{(o)}-E_{\text {neutral }} \\
& E A_{V}=E_{\text {neutral }}-E_{\text {anion }}^{(o)}
\end{aligned}
$$

The fundamental gap or quasi-particle gap (QP) was calculated as defined in the delta self-consistent field $(\triangle \mathrm{SCF})$ method $[50,51]$ :

$$
E_{Q P}=I E_{V}-E A_{V}=E_{\text {cation }}^{(o)}+E_{\text {anion }}^{(o)}-2 E_{\text {neutral }}
$$

Time-dependent density functional theory (TD-DFT) at B3LYP/6-31G* level was employed for the calculation of electronic excitations and UV-Visible absorption spectrum for each molecule. In the electronic absorption spectrum, the first peak corresponds to the first optically active transition $\mathrm{E}_{\mathrm{OPT}}$. From the $\mathrm{E}_{\mathrm{OPT}}$ value obtained from the spectrum, an estimate of the exciton binding energy was evaluated as [52,53]:

$$
E_{B I N D}=E_{Q P}-E_{O P T}
$$

All the DFT and TD-DFT calculations were performed using NWChem software package [54]. Moreover, geometry optimization of the molecules at B3LYP/6-31G* level of theory was also performed using Gaussian 16 software [55]. The molecular orbitals and electrostatic potentials mapped on the isosurfaces were visualized using ArgusLab (version 4.0) [56].

\subsection{Molecular Dynamics (MD) Simulations}

To address the solvent effects on equilibrium conformations of the investigated molecules, each molecule was inserted in a water box (Figure 2) with a minimum distance between any atom of 
each molecule and the edge of the box to be of $10 \AA$ using VMD software package. The force-field parameters for the molecules were obtained using the antechamber. The molecule was parameterized using AM1-BCC charge model and general amber force-field (GAFF) parameter was generated using antechamber module [57] of the Amber software package [58]. TIP3P model was used for water molecules. Each complex system (molecule + water box) was prepared using tleap program in the Amber software package. Each molecular system was energy minimized and gradual heating of the system to $300 \mathrm{~K}$ in steps of $30 \mathrm{~K}$ was performed [59,60]. Equilibration of the system was done for 3 $\mathrm{ns}$ and followed by a production run of $50 \mathrm{~ns}$ of molecular dynamics (MD) simulations. The NAMD software package [61] was used to perform MD simulations.

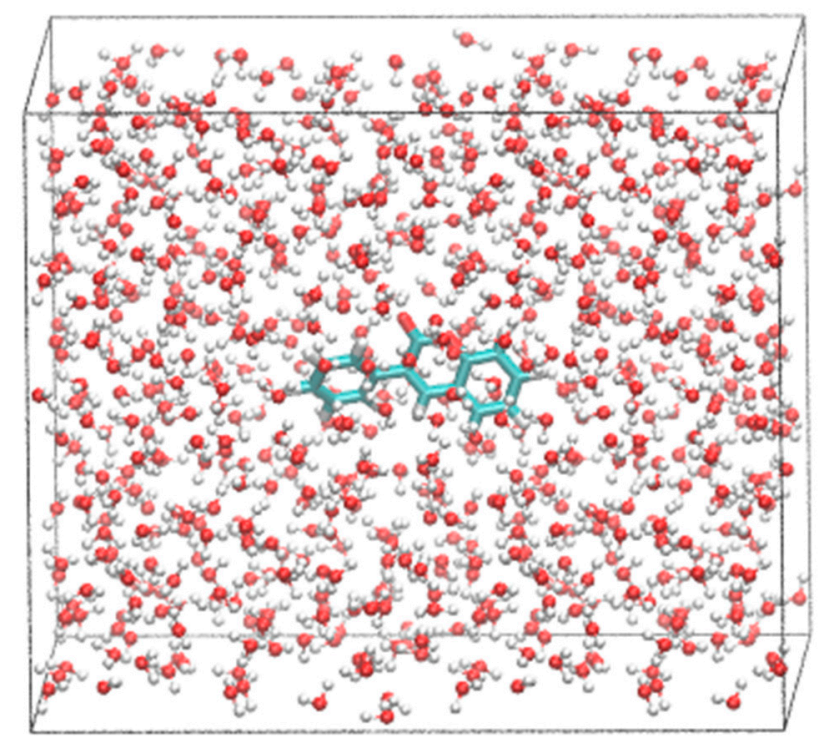

Figure 2. Molecular dynamics (MD) simulation of molecule A inserted in a water box of $\sim 710$ water molecules, with periodic boundary conditions.

\section{Results and Discussion}

All the five molecules (Figure 1) were subjected to geometry optimization without symmetry constraints using DFT method with B3LYP exchange correlation (XC) functional in combination with basis sets $6-31 G^{*}$ and $6-311+G^{*}$, alternatively. Coumarin molecule was chosen as the reference molecule, and availability of experimental data allowed to validate the computational approach employed in the present study. In Figure 3, comparison between the experimental infrared spectrum (available from NIST database) [62] and the calculated spectrum using DFT with B3LYP/6-311+G* for coumarin molecule is shown. In general, the computed harmonic frequencies overestimate the experimental values [62]; in particular noted for the main peak, representing $\mathrm{C}=\mathrm{O}$ (experimental value $1743 \mathrm{~cm}^{-1}$ ). Therefore, we performed a uniform scaling factor on the computed ones to provide a better match with the experimental vibrational frequencies [63]. Indeed, we achieved a reasonable agreement between the scaled vibrational frequency of main peak $\mathrm{C}=\mathrm{O}\left(1778 \mathrm{~cm}^{-1}\right)$ and the experimental value [62-64]. Overall, we note the blue shifted profile compared to the experimental IR spectra [62]. 


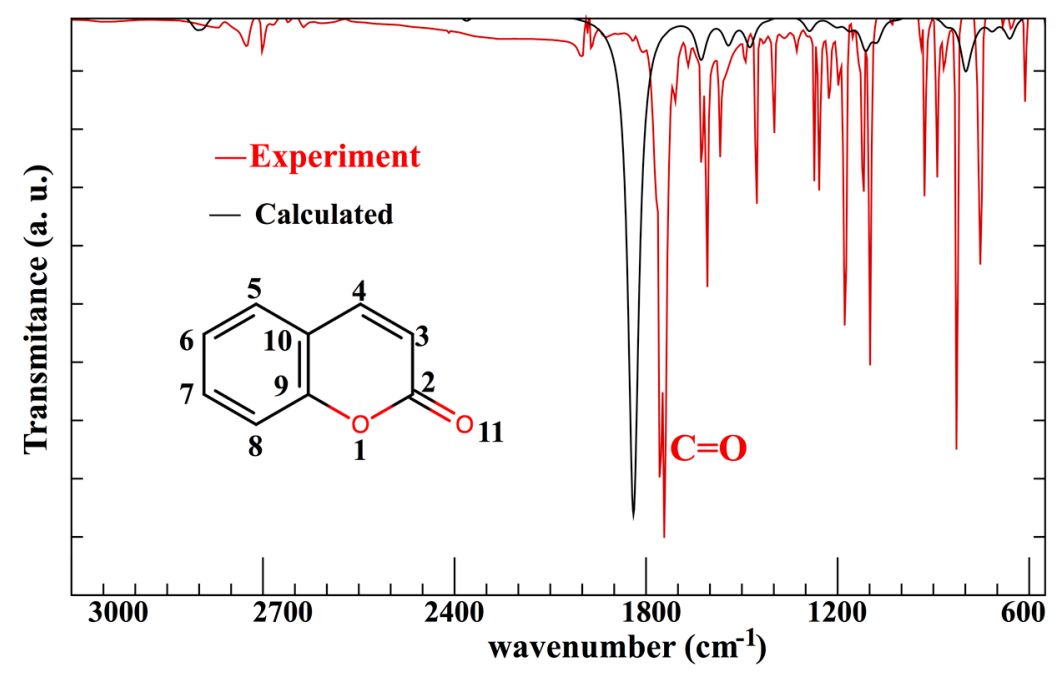

Figure 3. Infrared spectrum of coumarin experimental and calculated (B3LYP/6-3 $\left.3^{1} 1+\mathrm{G}^{*}\right)$ is shown here.

Overall, we note an excellent agreement (Table 1) between the computed and experimental bond distance data [65]. The maximum variation of $2 \%$ between the experimental and computed distance was found for $1 \mathrm{O}-2 \mathrm{C}$ bond length obtained by B3LYP/6-31G* and B3LYP/6-311+ $\mathrm{G}^{*}$ level of theory, while a variation of $3.5 \%$ by $\mathrm{PBE} / 6-31 \mathrm{G}^{*}$ calculations. In general, the bond lengths were found to be overestimated by PBE/6-31G* calculations (Table 1 ).

Compound $\mathbf{A}$ is a 3-phenylcoumarin; compound $\mathbf{B}$ is a 3-phenylcourmain derivative with bromine substitution in the phenyl ring and hydroxyl substitution in position 8 of the coumarin moiety. Compound $\mathrm{C}$ is also a 3-phenylcourmain derivative; however, with two hydroxyl substitutions in the meta-position of the coumarin moiety and one hydroxyl substitution in the external phenyl ring. Compound $\mathbf{D}$ is 3-heteroarylcoumarin (with a 2-thiophene group) with identical two-hydroxyl substitution (meta position) in the coumarin moiety as molecule $\mathbf{C}$.

Table 1. Comparison of optimized bond length distances for coumarin with corresponding experimental data. Variation in the bond lengths is reported in \%. The numbering scheme of coumarin molecule is same as shown in Figure 3. The bond lengths are reported in angstrom $(\AA)$, and up to four significant figures.

\begin{tabular}{|c|c|c|c|c|c|}
\hline Atom 1 & Atom 2 & Exp..$^{\neq}$ & B3LYP/6-31G* & B3LYP/6-311+G* & PBE/6-31G* \\
\hline $1 \mathrm{O}$ & $2 \mathrm{C}$ & 1.371 & $1.398(1.97 \%)$ & $1.396(1.82 \%)$ & $1.419(3.5 \%)$ \\
\hline $1 \mathrm{O}$ & $9 \mathrm{C}$ & 1.372 & $1.365(-0.5 \%)$ & $1.365(-0.5 \%)$ & $1.367(-0.36 \%)$ \\
\hline $2 \mathrm{C}$ & $11 \mathrm{O}$ & 1.216 & $1.208(-0.65 \%)$ & $1.202(-1.15 \%)$ & $1.217(0.08 \%)$ \\
\hline $2 \mathrm{C}$ & $3 \mathrm{C}$ & 1.454 & $1.460(0.4 \%)$ & $1.459(0.34 \%)$ & $1.459(0.34 \%)$ \\
\hline $3 C$ & $4 \mathrm{C}$ & 1.352 & $1.352(0 \%)$ & $1.349(-0.22 \%)$ & $1.363(0.81 \%)$ \\
\hline $4 \mathrm{C}$ & $10 \mathrm{C}$ & 1.440 & $1.442(0.13 \%)$ & $1.440(0 \%)$ & $1.441(0.07 \%)$ \\
\hline $5 \mathrm{C}$ & $10 \mathrm{C}$ & 1.406 & $1.407(0.07 \%)$ & $1.406(0 \%)$ & $1.414(0.57 \%)$ \\
\hline $5 \mathrm{C}$ & $6 \mathrm{C}$ & 1.388 & $1.388(0 \%)$ & $1.385(-0.22 \%)$ & $1.394(0.432 \%)$ \\
\hline $6 \mathrm{C}$ & $7 \mathrm{C}$ & 1.402 & $1.403(0.07 \%)$ & $1.402(0 \%)$ & $1.402(0 \%)$ \\
\hline $7 \mathrm{C}$ & $8 \mathrm{C}$ & 1.390 & $1.391(-0.07 \%)$ & $1.389(-0.07 \%)$ & $1.397(0.50 \%)$ \\
\hline $8 \mathrm{C}$ & $9 \mathrm{C}$ & 1.394 & $1.396(0.14 \%)$ & $1.394(0 \%)$ & $1.404(0.72 \%)$ \\
\hline $9 \mathrm{C}$ & $10 \mathrm{C}$ & 1.400 & $1.408(0.57 \%)$ & $1.405(0.36 \%)$ & $1.419(1.36 \%)$ \\
\hline
\end{tabular}

\subsection{Electronic Properties of the Compounds Using B3LYP XC Functional}

The calculated electronic properties of the compounds are summarized in Table 2 . The chemical reactivity of the molecule can be described by the energy of the lowest unoccupied molecular orbital $\left(\mathrm{E}_{\mathrm{LUMO}}\right)$ that defines the electron accepting ability, while the energy of the highest occupied molecular 
orbital $\left(\mathrm{E}_{\mathrm{HOMO}}\right)$ is the one that defines the electron donating ability. The combination of the two parameters ( $\left.\mathrm{E}_{\mathrm{LUMO}}, \mathrm{E}_{\mathrm{HOMO}}\right)$ can then be used to estimate the electronic chemical potential (Equation (1), methods) and chemical hardness (Equation (2)) of the molecules. The higher the value of $\mathrm{E}_{\mathrm{HOMO}}$, the easier it becomes to donate an electron, while lower the value of $\mathrm{E}_{\mathrm{LUMO}}$ easier it becomes to accept an electron. Among the investigated coumarin derivatives, compound $\mathbf{D}$ displays the most favorable electron donating $\left(\mathrm{E}_{\mathrm{HOMO}}\right)$, and compound $\mathbf{B}$ the most favorable electron accepting $\left(\mathrm{E}_{\mathrm{LUMO}}\right)$ ability. It is worth mentioning that the electron donating capability of molecule $\mathbf{C}$ is quite close to that of compound $\mathbf{D}$. The smaller the difference energy between the $\mathrm{E}_{\mathrm{LUMO}}$ and $\mathrm{E}_{\mathrm{HOMO}}$ values, the higher the reactivity of the molecule. Compound $\mathbf{D}$ represents highest reactivity, while the other three derivatives displayed very similar values. The $\mathrm{E}_{\mathrm{LUMO}}-\mathrm{E}_{\mathrm{HOMO}}(\Delta \mathrm{E})$ gap also provides a measure of the chemical hardness of the molecule. A smaller value of $\Delta \mathrm{E}$ corresponds to a soft molecule. Substitution of sulfur atom in a molecule has been suggested to decrease the global hardness of the molecule. Indeed, compound $\mathbf{D}$, which contains sulfur atoms, displays the lowest value of $\Delta \mathrm{E}$ (Figure 1). For the chemical potential, compound $\mathbf{B}$ displays the lowest value, thus best electron acceptor (higher electronegativity) among the other coumarin derivatives.

Table 2. Electronic properties of the Coumarin and derived compounds $\mathbf{A}, \mathbf{B}, \mathbf{C}$ and $\mathbf{D}$, employing B3LYP XC in combination with basis set 6-31G*, and 6-311+G* (red).

\begin{tabular}{|c|c|c|c|c|c|c|c|c|c|c|}
\hline \multirow{2}{*}{$\begin{array}{c}\text { Compound } \\
\text { E }_{\text {HOMO }}(\mathrm{eV})\end{array}$} & \multicolumn{2}{|c|}{ Coumarin } & \multicolumn{2}{|c|}{$\mathbf{A}$} & \multicolumn{2}{|c|}{ B } & \multicolumn{2}{|c|}{$\mathrm{C}$} & \multicolumn{2}{|c|}{ D } \\
\hline & -6.50 & -6.87 & -6.07 & -6.45 & -6.26 & -6.59 & -5.61 & -6.04 & -5.58 & -5.97 \\
\hline $\mathrm{E}_{\mathrm{LUMO}}(\mathrm{eV})$ & -1.88 & -2.28 & -2.04 & -2.32 & -2.23 & -2.58 & -1.71 & -2.14 & -2.04 & -2.48 \\
\hline$\eta=\left(E_{\text {LUMO }}-E_{\mathrm{HOMO}}\right) / 2(\mathrm{eV})$ & 2.31 & 2.30 & 2.01 & 2.07 & 2.01 & 2.01 & 1.95 & 1.95 & 1.77 & 1.75 \\
\hline $\mathrm{CP}=\left(\mathrm{E}_{\mathrm{LUMO}}+\mathrm{E}_{\mathrm{HOMO}}\right) / 2(\mathrm{eV})$ & -4.19 & -4.58 & -4.05 & -4.39 & -4.25 & -4.59 & -3.66 & -4.09 & -3.81 & -4.23 \\
\hline Ionization energy $\mathrm{IE}_{\mathrm{V}}(\mathrm{eV})$ & 8.41 & $8.71^{\neq}$ & 7.64 & 7.96 & 7.72 & 7.98 & 7.11 & 7.48 & 7.14 & 7.46 \\
\hline Electron affinity $\mathrm{EA}_{\mathrm{V}}(\mathrm{eV})$ & -0.04 & 0.49 & 0.35 & 0.80 & 0.67 & 1.09 & 0.15 & 0.65 & 0.48 & 1.00 \\
\hline Quasi particle gap $\mathrm{E}_{\mathrm{QP}}(\mathrm{eV})$ & 8.45 & 8.22 & 7.29 & 7.16 & 7.05 & 6.89 & 6.96 & 6.83 & 6.66 & 6.46 \\
\hline
\end{tabular}

Subsequently, the vertical ionization energies $\left(\mathrm{IE}_{\mathrm{V}}\right.$, see Equation (3)) and the electron affinities $\left(E A_{V}\right.$, see Equation (4)) values were calculated on the fixed geometries of the molecules in their ground state configuration. With respect to the coumarin molecule, all the coumarin derivatives displayed lower $\mathrm{IE}_{\mathrm{V}}$ values while higher $\mathrm{EA}_{\mathrm{V}}$ values. Among the coumarin derivatives, compounds $\mathbf{A}$ and $\mathbf{B}$ displayed the highest value for $\mathrm{IE}_{\mathrm{V}}$, and compound $\mathbf{B}$ the highest value of $E A_{V}$.

To address the reliability of the electronic structure calculations, we repeated DFT calculations using B3LYP XC functional with $6-311+G^{*}$ basis set. The general trend in the calculated values among the coumarin derivatives is nicely reproduced. Note that there is a marginal increase by $\sim 4 \%$ for the $\mathrm{IE}_{\mathrm{V}}$ values. Moreover, the calculated $\mathrm{IE}_{\mathrm{V}}$ for coumarin molecule $8.71 \mathrm{eV}$ is very close to the experimental value $(8.72 \mathrm{eV})$ [66]. A significant difference between the calculated $\mathrm{EA}_{\mathrm{V}}$ values using the two basis sets was observed. The noted increase in the $E A_{V}$ using $6-311+G^{*}$ basis sets consistent with previous other studies $[38,48,67]$, as including diffusion functions can improve the predicted properties of anionic species.

\subsection{Electronic Properties of the Compounds Using PBE XC Functional}

To further affirm our results, we repeated the electronic structure calculations with PBE XC functional and 6-31G* basis set, since due to the computational efficiency it is considered as a reference XC functional. In Table 3, the calculated observables obtained using PBE XC functional and the associated difference with respect to B3LYP XC functional is reported. The $\triangle \mathrm{E}$ gap and $\mathrm{IE}_{\mathrm{V}}$ values are underestimated, while $E A_{V}$ value is overestimated for the compounds using PBE XC functional. However, the general trend of the calculated observables among the compounds remains consistent (Table 3). 
Table 3. Electronic properties of the Coumarin and derived compounds A, B, C and D, employing PBE $\mathrm{XC}$ in combination with basis set $6-31 \mathrm{G}^{*}$, and difference between two functionals ( $\Delta=$ B3LYP-PBE).

\begin{tabular}{|c|c|c|c|c|c|c|c|c|c|c|}
\hline Compound & Coum & rin & $\mathbf{A}$ & & B & & $\mathrm{C}$ & & $\mathbf{D}$ & \\
\hline Properties & PBE & $\Delta$ & PBE & $\Delta$ & PBE & $\Delta$ & PBE & $\Delta$ & PBE & $\Delta$ \\
\hline $\mathrm{E}_{\mathrm{HOMO}}(\mathrm{eV})$ & & -0.78 & -5.39 & -0.68 & & -0.75 & -5.01 & -0.6 & -4.88 & -0.7 \\
\hline$(\mathrm{eV})$ & -2.60 & 0.72 & -2.66 & 0.62 & -2.89 & 0.66 & -2.53 & 0.82 & -2.63 & 0.59 \\
\hline$\left.-\mathrm{E}_{\mathrm{HOMO}}\right) / 2(\mathrm{eV})$ & 1.56 & 0.75 & 1.37 & 0.64 & 1.31 & 0.7 & 1.24 & 0.71 & 13 & 0.64 \\
\hline $\mathrm{CP}=\left(\mathrm{E}_{\mathrm{LUMO}}+\mathrm{E}_{\mathrm{HOMO}}\right) / 2(\mathrm{eV})$ & -4.16 & -0.03 & -4.03 & -0.02 & -4.2 & -0.05 & -3.77 & 0.11 & -3.76 & -0.05 \\
\hline Ionization energy $\mathrm{IE}_{\mathrm{V}}(\mathrm{eV})$ & 8.28 & 0.13 & 7.47 & 0.17 & 7.42 & 0.3 & 6.98 & 0.13 & 6.93 & 0.21 \\
\hline Electron affinity EA $\mathrm{V}_{\mathrm{V}}(\mathrm{eV})$ & 0.07 & -0.11 & 0 51 & -0.16 & 0.80 & -0.13 & 0.41 & -0.26 & 0.54 & -0.06 \\
\hline Quasi particle gap $\mathrm{E}_{\mathrm{QP}}(\mathrm{eV})$ & 8.21 & 0.24 & 6.96 & 0.33 & 6.62 & 0.43 & 6.57 & 0.39 & 6.39 & 0.27 \\
\hline
\end{tabular}

\subsection{Molecular Orbitals and Electrostatic Potentials}

The frontier orbitals (FOs) of the investigated compounds are depicted in Figure 4. For each molecule, both the HOMO and LUMO, are $\pi$-type and delocalized over-all the molecule. In particular, all the LUMOs are quite similar and mainly composed by the atomic orbitals of the coumarin moiety, with only small contributions from those of the substituents.

As far as the HOMOs are concerned, the contributions from the substituents are much more relevant and consequently, these orbitals are more different between them in comparison with the LUMOs case. Therefore, larger differences between the energies of the HOMOs of the molecules A-D and that of the parent compound are expected in comparison with those of the LUMOs. Indeed, HOMO-LUMO gaps are smaller for the coumarin derivatives with respect to the parent compound.
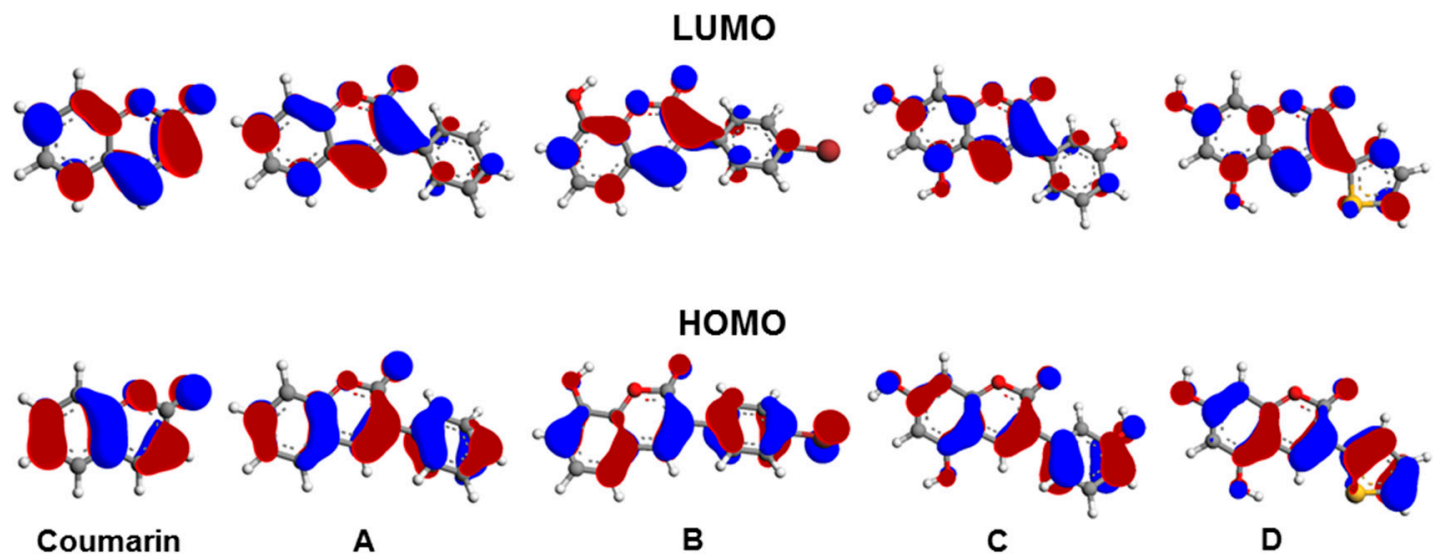

Figure 4. Frontier molecular orbitals of coumarin and molecules A-D calculated by density functional theory (DFT) at B3LYP/6-31G* level of theory (contour plot 0.04).

Figure 5 reports, for each compound, the electrostatic potential (EP) mapped onto the density surface. As expected on the base of the electronegativity, the parts of surfaces with the highest negative charge are those in the correspondence with the oxygen atoms, especially those doubly bound in the pyrone rings. Taking into account the effects of the substituents at the parent molecule, the hydroxide groups regardless the position, present negative EPs at the oxygen atoms, whereas the hydrogen involved in $\mathrm{OH}$ bonds are in the correspondence with the regions of the surfaces with the more positive potentials (molecules B, C and D). The phenyl rings show electronic density delocalized over the carbon atoms skeleton and positive EPs at the hydrogen ones (molecules A, B and C). 


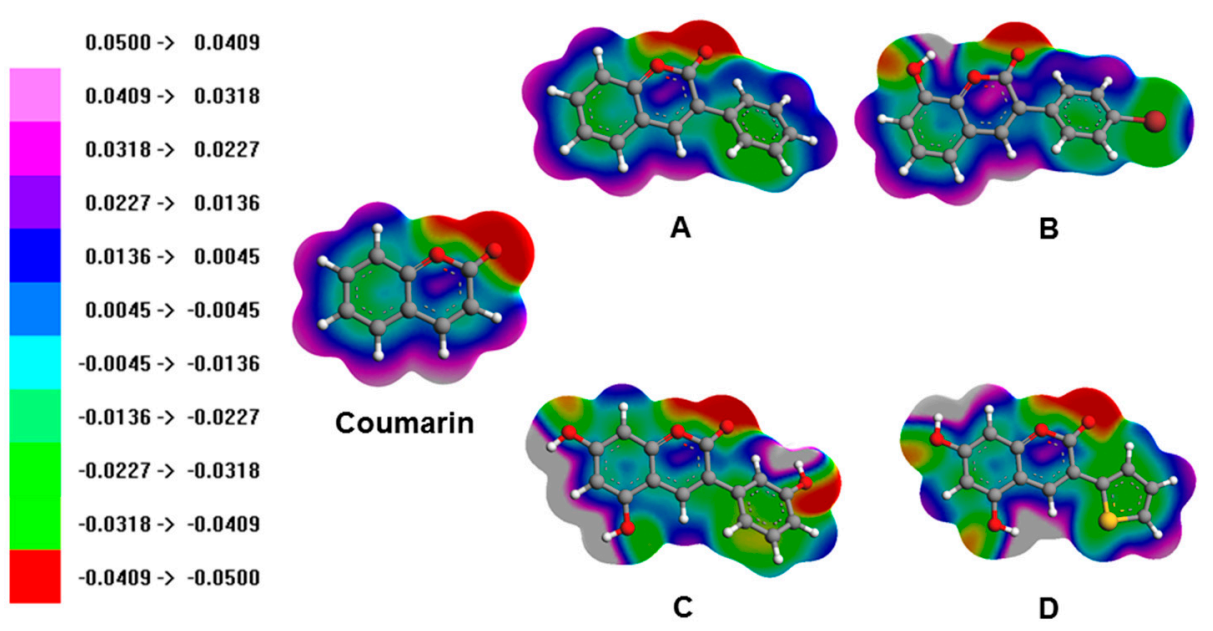

Figure 5. Electrostatic potentials mapped on electron density isosurfaces for coumarin and molecules A-D calculated by DFT (contour plot 0.002). The colors are mapped in accordance with the EP at the point on the isosurfaces.

The thiophene ring exhibits similar properties with an important negative contribution at the sulphur atom (compound D). Interestingly, the bromine atom in the molecule $\mathbf{B}$ presents an anisotropic $\mathrm{EP}$ with negative values around the $\mathrm{C}$-Br bond and a $\sigma$-hole at the tip of the halogen atom.

\subsection{Optical Properties}

Time-dependent density function theory method was employed at B3LYP/6-31G* and B3LYP/6-311+ $\mathrm{G}^{*}$ levels to calculate the absorption spectra of the compounds optimized ground state structure in the gaseous phase. The peaks in the absorption spectrum reported with a Lorentzian broadening allowed characterizing the behavior of the molecules when irradiated. The first absorption peak corresponds to the optical onset of the compound and the main peak corresponds to the one with the maximum value of transition intensity (Figure 6).

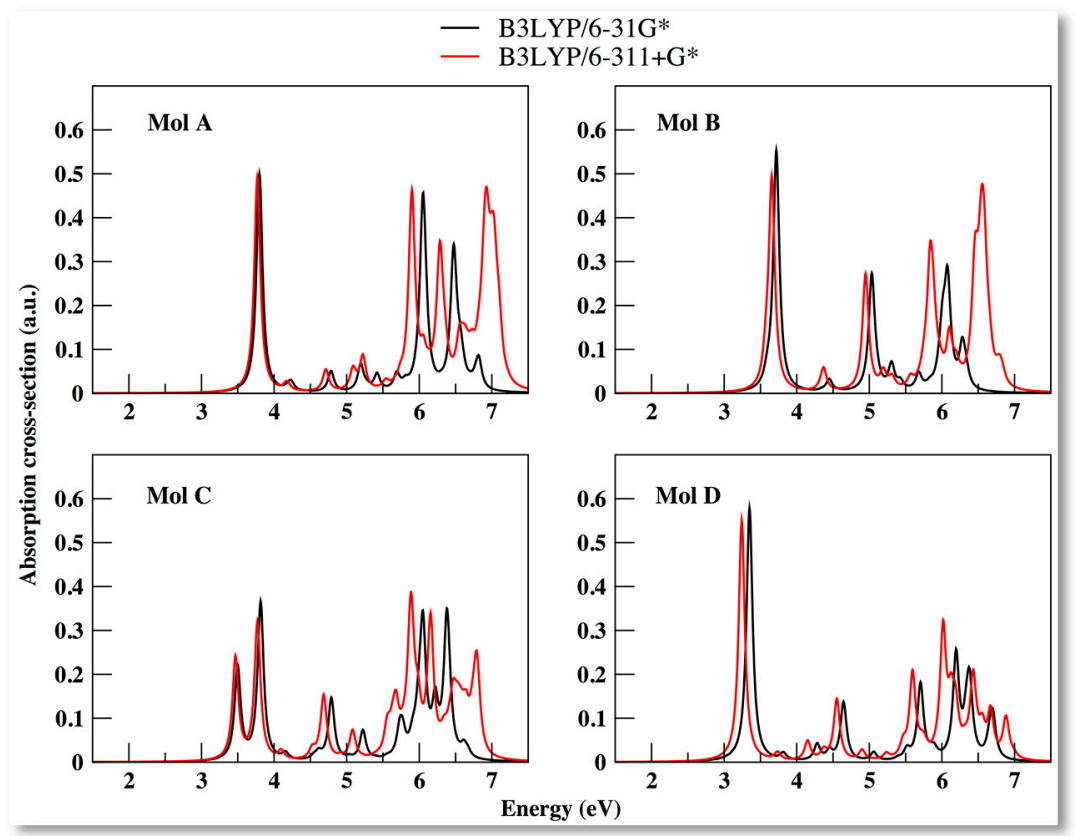

Figure 6. Calculated absorption spectra of coumarin derivatives using B3LYP XC functional with 6-31G* (black) and 6-311+G* (red) basis sets, respectively. 
All the four derivatives display optical onset in the near ultra-violet (UV) region, ranging between [3.26-3.94] eV. In general, using 6-311+ $\mathrm{G}^{*}$ basis set, the absorption profile was found to be red-shifted with respect to $6-31 G^{*}$ basis set, and with a reasonable overlap in the first peak of absorption. Significant difference in the absorption profile between the basis sets in found in the 5 to $7 \mathrm{eV}$ range, which corresponds to deep UV (UV-C) region. Among the derivatives, compounds A B and C displayed a good overlap in the UV-B [3.5-4.0 eV] and UV-C [5.5-6.2 eV] regions, thus suggesting an optical signature of a phenylcoumarin derivative. On the other hand, for compound $\mathbf{D}$ (belonging to heteroarylcoumarin family) the optical onset value was red-shifted with respect to the other derivatives.

To obtain the electronic absorption characteristics of the derivatives TD-DFT calculations were repeated with PBE/6-31G* level of description (Figure 7). Consistent with our previous findings, we note a general red-shifted absorption profile with respect to the B3LYP XC functional (Table 4). Interestingly, we note for compound $\mathbf{B}(2.92 \mathrm{eV}), \mathbf{C}(2.75 \mathrm{eV})$ and $\mathbf{D}(2.98 \mathrm{eV})$ the first signs of optical transition to occur in the visible region (between blue and violet).

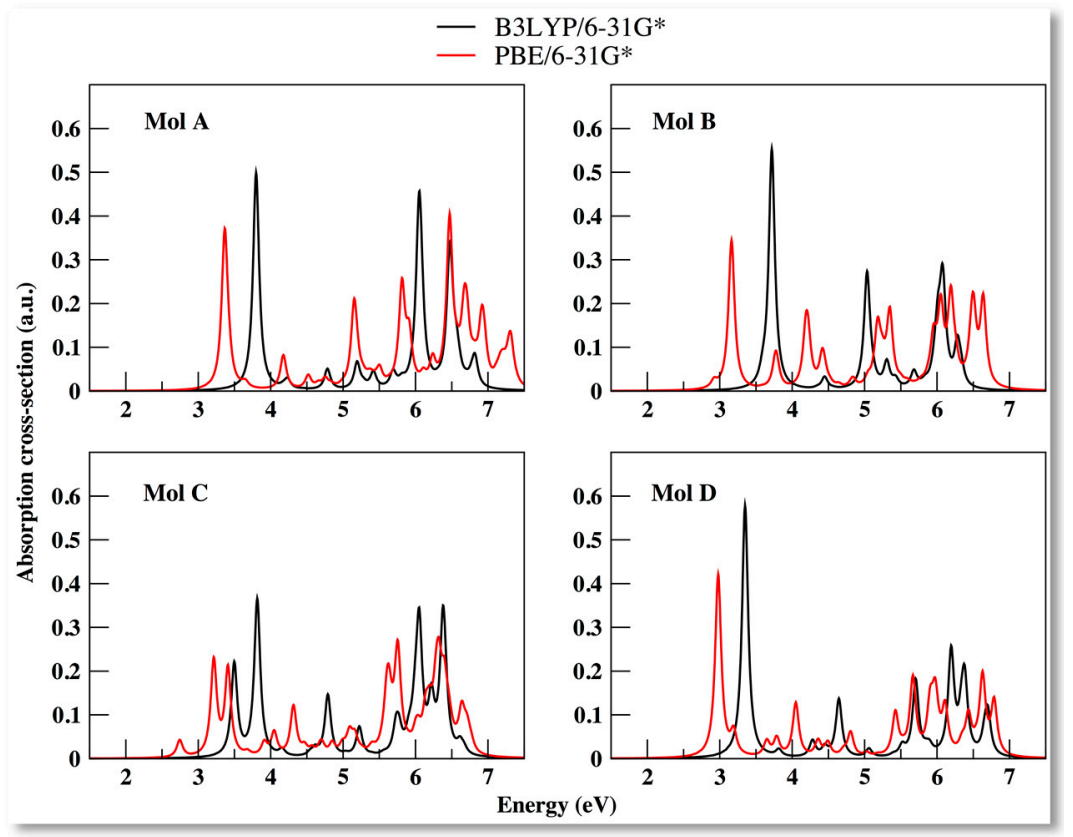

Figure 7. Calculated absorption spectra of coumarin derivatives using PBE XC functional (red) and B3LYP (black) and with 6-31G* basis set, respectively.

For the optical structure one can obtain information about the transition intensity, the transition weight (indicating the dominant transition), and also the type of the transition itself, which will be discussed in the next section. In Table 4 is summarized the transition energy and relative transition intensity (given as oscillator strength) for the main peak (MP) absorption and the $\mathrm{E}_{\mathrm{OPT}}$ (first signs of optical transition) value employing two XC functionals and basis sets.

Table 4. Energy and oscillator strength (OS) for the main peak (MP) and optical onset (EOPT) extracted from the absorption spectra.

\begin{tabular}{|c|c|c|c|c|c|c|c|c|c|c|c|c|}
\hline \multirow{3}{*}{ Molecule } & \multicolumn{4}{|c|}{ B3LYP/6-31G* } & \multicolumn{4}{|c|}{ B3LYP/6-311+G* } & \multicolumn{4}{|c|}{ PBE/6-31+G* } \\
\hline & \multicolumn{2}{|c|}{ Main Peak } & \multicolumn{2}{|c|}{$\mathrm{E}_{\mathrm{OPT}}$} & \multicolumn{2}{|c|}{ Main Peak } & \multicolumn{2}{|c|}{$\mathrm{E}_{\mathrm{OPT}}$} & \multicolumn{2}{|c|}{ Main Peak } & \multicolumn{2}{|c|}{$\mathrm{E}_{\mathrm{OPT}}$} \\
\hline & eV & OS & eV & OS & eV & OS & eV & OS & eV & OS & eV & OS \\
\hline A & 3.80 & 0.50 & 3.80 & 0.50 & 3.77 & 0.49 & 3.77 & 0.49 & 6.47 & 0.38 & 3.37 & 0.35 \\
\hline B & 3.72 & 0.55 & 3.59 & 0.02 & 3.66 & 0.48 & 3.58 & 0.06 & 3.16 & 0.34 & 2.92 & 0.02 \\
\hline $\mathrm{C}$ & 3.82 & 0.36 & 3.50 & 0.21 & 5.89 & 0.38 & 3.47 & 0.23 & 6.32 & 0.14 & 2.74 & 0.04 \\
\hline D & 3.35 & 0.58 & 3.35 & 0.58 & 3.24 & 0.55 & 3.24 & 0.55 & 2.98 & 0.42 & 2.98 & 0.42 \\
\hline
\end{tabular}


For molecules A and D using B3LYP XC with either of the basis sets, we found the MP and optical onset values to coincide. On the other hand, using PBE/6-31G* we found the coincidence between the MP and optical onset only for molecule $\mathbf{D}$ (Table 4).

Using the information obtained for the optical onset values, we further evaluated the exciton binding energy ( $E_{\text {BIND }}$ ) values (see Equation (6)), defined as energy needed to dissociate an excited electron-hole pair into free charge carriers. In Table 5, we summarize the exciton binding energy values of the molecules using the choses XC functionals and the basis sets.

Among the molecules, A displayed the highest value of exciton binding energy, $\mathbf{D}$ the lowest, and $\mathbf{B}$ and $\mathbf{C}$ displayed similar energy values (Table 5). Thus, suggesting that adding a hydroxyl substitution in the coumarin motif (between $\mathbf{B}$ and $\mathbf{C}$ ) does not change the exciton binding energy. The $E_{B I N D}$ trend among the molecules remains consistent also for calculations with B3LYP/6-311+G*, however, with the $E_{B I N D}$ values reduced between 3-6\%. On the other hand, we note a maximum increase of $10.7 \%$ for molecule $C$ for the calculations with PBE/6-31G* model.

Table 5. Optical onset and exciton binding ( $\left.\mathrm{E}_{\mathrm{BIND}}\right)$ energy values are reported here. The symbol $(\downarrow)$ is denotes a decrease and $(\uparrow)$ denotes an increase in the values with respect to B3LYP/6-31G* level of description.

\begin{tabular}{|c|c|c|c|c|c|c|}
\hline \multirow{2}{*}{$\begin{array}{l}\text { Molecule } \\
(\mathrm{eV})\end{array}$} & \multicolumn{2}{|c|}{ B3LYP/6-31G* } & \multicolumn{2}{|c|}{ B3LYP/6-311+G* } & \multicolumn{2}{|c|}{ PBE/6-31+G* } \\
\hline & $\mathrm{E}_{\mathrm{OPT}}$ & $\mathrm{E}_{\text {BIND }}$ & $\mathrm{E}_{\mathrm{OPT}}$ & E BIND & $\mathrm{E}_{\mathrm{OPT}}$ & EBIND \\
\hline A & 3.80 & 3.49 & $3.77 \downarrow$ & $3.36 \downarrow(3.4 \%)$ & $3.37 \downarrow$ & $3.59 \uparrow(2.9 \%)$ \\
\hline B & 3.59 & 3.46 & $3.58 \downarrow$ & $3.31 \downarrow(4.3 \%)$ & $2.92 \downarrow$ & $3.70 \uparrow(6.9 \%)$ \\
\hline $\mathrm{C}$ & 3.50 & 3.46 & $3.47 \downarrow$ & $3.33 \downarrow(3.8 \%)$ & $2.74 \downarrow$ & $3.83 \uparrow(10.7 \%)$ \\
\hline D & 3.35 & 3.31 & $3.24 \downarrow$ & $3.11 \downarrow(6 \%)$ & $2.98 \downarrow$ & $3.41 \uparrow(3 \%)$ \\
\hline
\end{tabular}

\subsection{Solvent Effects on the Absorption Spectra for the Coumarin Derivatives}

In order not to utterly neglect possible solvent effects on equilibrium conformations of the coumarin derivatives, and therefore, indirectly, on their optical properties, we performed classical MD simulations for the molecules in water. The representative conformation of the four compounds in water was extracted and the spectra was calculated for these geometries and compared with those of the vacuum-optimized one (Figure 8). For all the representative molecular structures in solvent, the optical onset is red-shifted with respect to the vacuum ones. Only in the case of molecule $\mathbf{D}$ (which belongs to heteroarylcoumarin family) the main absorption peak is nearly unchanged in the position with respect to the vacuum optimized structure. Furthermore, the oscillator strength of the main peak is lower only for molecule $\mathbf{D}$ for the TD-DFT calculations performed on the representative molecular structures obtained from classical MD simulations in water. Thus, a clear difference with respect to impact of solvent on the absorption characteristics is noted between the heteroarylcoumarin (D) and 3-phenylcoumarin (A, B, C) derivatives.

It is evident from the absorption spectrum that molecular structures occur in the UV region (Figure 8). Therefore, one could expect the main absorption peak of the coumarin derivatives to be located in the UV region. Regarding the solvent optimized structures of $\mathbf{A}, \mathbf{B}$ and $\mathbf{D}$, the optical onset and the main absorption peak are the same, and the transitions involve an excitation of the HOMO-LUMO states (Table 6). This optical feature is conserved only for the optimized structures of A and $\mathbf{D}$ in vacuum (Table 4). In detail, with the solvent treatment, the main absorption peak of molecules A, B and $\mathbf{D}$ represent excitation from the HOMO $\rightarrow$ LUMO level, while for $\mathbf{C}$ from HOMO- $\rightarrow$ LUMO level (Table 6). Overall, among the molecules, the optical features display same trend between the vacuum and solvent treatment. 


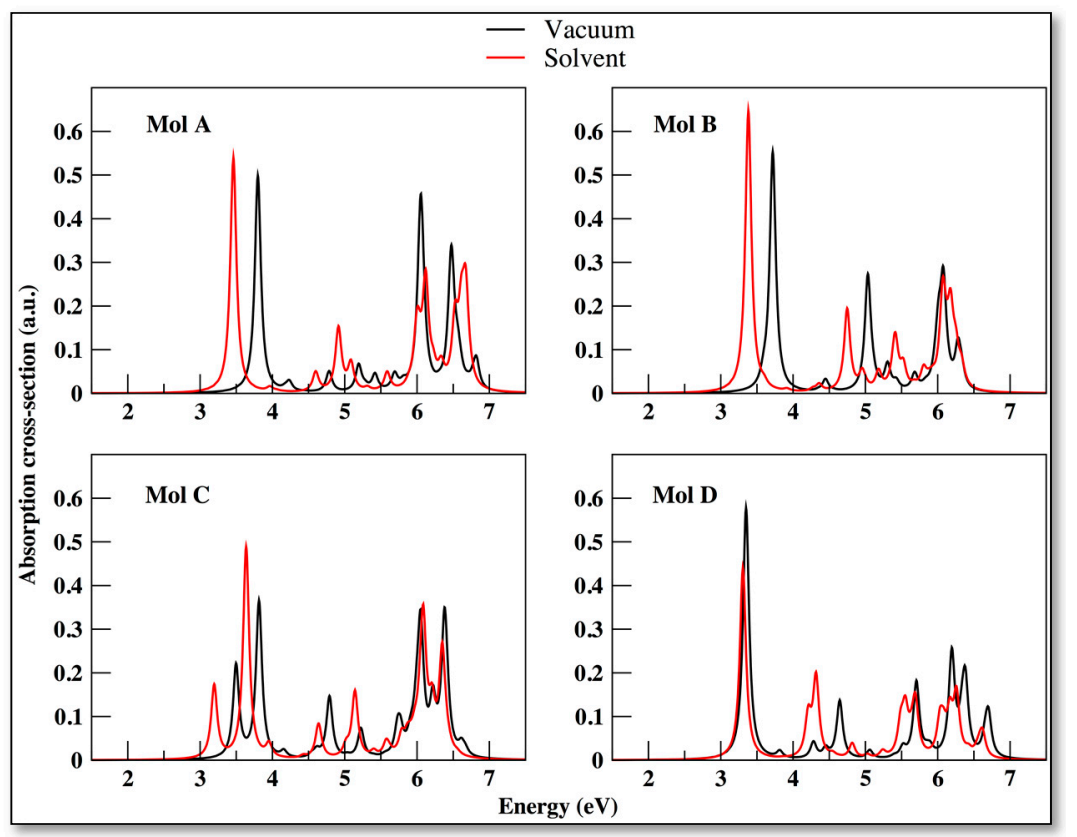

Figure 8. Absorption spectra of coumarin derivatives in vacuum (black) and solvent (red) calculated with B3LYP/6-31G* model.

Table 6. Main absorption peak energy value, oscillator strength (OS) and their associated electronic excitations transition for the vacuum and solvent model systems, are included here. The transition weight is reported in \%, and $\mathrm{H}$ stands for HOMO and L for LUMO.

\begin{tabular}{|c|c|c|c|c|c|c|}
\hline \multirow[t]{2}{*}{ Molecule } & \multicolumn{3}{|c|}{ B3LYP/6-31G* (Vacuum) } & \multicolumn{3}{|c|}{ B3LYP/6-31G* (Water) } \\
\hline & $\mathrm{MP}(\mathrm{eV})$ & OS & Transition & $\mathrm{MP}(\mathrm{eV})$ & OS & Transition \\
\hline $\mathbf{A}$ & 3.80 & 0.5 & $\mathrm{H} \rightarrow \mathrm{L}(96.3 \%)$ & 3.46 & 0.54 & $\mathrm{H} \rightarrow \mathrm{L}(98 \%)$ \\
\hline B & 3.72 & 0.55 & $\mathrm{H} \rightarrow \mathrm{L}(82.6 \%)$ & 3.38 & 0.65 & $\mathrm{H} \rightarrow \mathrm{L}(98 \%)$ \\
\hline $\mathrm{C}$ & 3.82 & 0.36 & $\mathrm{H}-1 \rightarrow \mathrm{L}(79.4 \%)$ & 3.64 & 0.49 & $\mathrm{H}-1 \rightarrow \mathrm{L}(81 \%)$ \\
\hline D & 3.35 & 0.58 & $\mathrm{H} \rightarrow \mathrm{L}(97.8 \%)$ & 3.31 & 0.44 & $\mathrm{H} \rightarrow \mathrm{L}(97 \%)$ \\
\hline
\end{tabular}

\section{Conclusions}

The aim of this work was to investigate the wide-range utility of coumarin derivatives used as enzyme inhibitors, three 3-phenylcoumarin (A, B, C), and one 3-heteroarylcoumarin (D) compounds. In particular, we examined the molecular structure, the electronic states (HOMO, LUMO), vertical ionization potential $\left(\mathrm{IE}_{\mathrm{V}}\right)$ and electron affinity, quasi-particle gap, and optical properties of the compounds using DFT and TD-DFT methods. Coumarin was chosen as a reference molecule, considering the existence of experimental data. A good match between the calculated and experimental $\mathrm{IE}_{\mathrm{V}}$ values supported the adopted computational approach. The reliability of the computed data was verified using two XC functionals (B3LYP, PBE) and two basis sets $\left(6-31 \mathrm{G}^{*}, 6-311+\mathrm{G}^{*}\right)$.

Molecule $\mathbf{B}$ displayed the highest value of $\mathrm{IE}_{\mathrm{V}}$ and $\mathrm{EA}_{\mathrm{V}}$, while molecule $\mathbf{D}$ had the lowest HOMO-LUMO energy gap value. Concerning the optical properties, all the molecules showed first-signs of absorption (optical onset $\mathrm{E}_{\mathrm{OPT}}$ ) in the UV-region with molecule $\mathbf{D}$ displaying the lowest $\mathrm{E}_{\mathrm{OPT}}$ and exciton binding ( $\mathrm{E}_{\mathrm{BIND}}$ ) energy values. The exciton energy values found lie in the range of wide band gap semiconductor materials.

To address solvent effects on the optical properties, TD-DFT calculation was performed on the extracted representative molecular structures from MD simulations in water. The first absorption peak was found to be red shifted with respect to calculations performed on geometries optimized in vacuum. Interestingly, same dominant HOMO-LUMO transition levels for the main absorption peak (and the optical onset) was prominent between the molecular structures in vacuum and their solvent counterparts. 
In conclusion, we provide valuable information that can inspire further research on coumarin-based derivatives as wide band gap semiconductor materials for applications in optoelectronic devices, and promote the use of DFT based computational methodology to identify and design novel molecules with useful and interesting applications.

Author Contributions: Conceptualization, A.K., A.F., L.P. and G.G.; Data curation, A.K.; Formal analysis, A.K., R.B., A.C., L.P. and G.G.; Funding acquisition, G.G.; Investigation, A.K., R.B., A.F. and L.P.; Methodology, A.K.; Resources, G.G.; Validation, A.K., A.C., L.P. and G.G.; Writing-original draft, A.K.; Writing-review \& editing, A.K., R.B., A.F., A.C., L.P. and G.G. All authors have read and agreed to the published version of the manuscript.

Funding: This work was partially supported by University of Cagliari.

Acknowledgments: A.K. acknowledges the use of high performance computing facility resources of CRS4, with special thanks to Marco Moro for his constant help and assistance.

Conflicts of Interest: The authors declare no conflict of interest.

\section{References}

1. Musa, M.A.; Cooperwood, J.S.; Khan, M.O. A review of coumarin derivatives in pharmacotherapy of breast cancer. Curr. Med. Chem. 2008, 15, 2664-2679. [CrossRef]

2. Borges, F.; Roleira, F.; Milhazes, N.; Santana, L.; Uriarte, E. Simple coumarins and analogues in medicinal chemistry: Occurrence, synthesis and biological activity. Curr. Med. Chem. 2005, 12, 887-916. [CrossRef] [PubMed]

3. Geen, G.R.; Evans, J.M.; Vong, A.K.; Katritzky, A.R.; Rees, C.W.; Scriven, E.F.V. Pyrans and their Benzo Derivatives: Applications. In Comprehensive Heterocyclic Chemistry II; Lan, R., Katritzky, C.W.R., Scriven, E.F.V., Eds.; Pergamon Press: Oxford, UK, 1997; pp. 469-500.

4. Egan, D.; O'Kennedy, R.; Moran, E.; Cox, D.; Prosser, E.; Thornes, R.D. The pharmacology, metabolism, analysis, and applications of coumarin and coumarin-related compounds. Drug Metab. Rev. 1990, 22, 503-529. [CrossRef] [PubMed]

5. Curini, M.; Cravotto, G.; Epifano, F.; Giannone, G. Chemistry and biological activity of natural and synthetic prenyloxycoumarins. Curr. Med. Chem. 2006, 13, 199-222. [CrossRef] [PubMed]

6. Anand, P.; Singh, B.; Singh, N. A review on coumarins as acetylcholinesterase inhibitors for Alzheimer's disease. Biorg. Med. Chem. 2012, 20, 1175-1180. [CrossRef]

7. Liu, X.; Cole, J.M.; Waddell, P.G.; Lin, T.-C.; Radia, J.; Zeidler, A. Molecular Origins of Optoelectronic Properties in Coumarin Dyes: Toward Designer Solar Cell and Laser Applications. J. Phys. Chem. A 2011, 116, 727-737. [CrossRef]

8. Barot, K.P.; Jain, S.V.; Kremer, L.; Singh, S.; Ghate, M.D. Recent advances and therapeutic journey of coumarins: Current status and perspectives. Med. Chem. Res. 2015, 24, 2771-2798. [CrossRef]

9. Delogu, G.L.; Matos, M.J. Coumarins as Promising Scaffold for the Treatment of Age-related DiseasesAn Overview of the Last Five Years. Curr. Top. Med. Chem. 2017, 17, 3173-3189. [CrossRef]

10. Fais, A.; Corda, M.; Era, B.; Fadda, M.B.; Matos, M.J.; Quezada q, E.; Santana, L.; Picciau, C.; Podda, G.; Delogu, G. Tyrosinase Inhibitor Activity of Coumarin-Resveratrol Hybrids. Molecules 2009, 14, 2514-2520. [CrossRef]

11. Sandhu, S.; Bansal, Y.; Silakari, O.; Bansal, G. Coumarin hybrids as novel therapeutic agents. Biorg. Med. Chem. 2014, 22, 3806-3814. [CrossRef]

12. Orallo, F. Trans-resveratrol: A magical elixir of eternal youth? Curr. Med. Chem. 2008, 15, 1887-1898. [CrossRef] [PubMed]

13. Fais, A.; Era, B.; Asthana, S.; Sogos, V.; Medda, R.; Santana, L.; Uriarte, E.; Matos, M.J.; Delogu, F.; Kumar, A. Coumarin derivatives as promising xanthine oxidase inhibitors. Int. J. Biol. Macromol. 2018, 120 Pt A, 1286-1293. [CrossRef]

14. Stefanachi, A.; Leonetti, F.; Pisani, L.; Catto, M.; Carotti, A. Coumarin: A Natural, Privileged and Versatile Scaffold for Bioactive Compounds. Molecules 2018, 23, 250. [CrossRef] [PubMed]

15. Seo, K.D.; Song, H.M.; Lee, M.J.; Pastore, M.; Anselmi, C.; De Angelis, F.; Nazeeruddin, M.K.; Gräetzel, M.; Kim, H.K. Coumarin dyes containing low-band-gap chromophores for dye-sensitised solar cells. Dyes Pigments 2011, 90, 304-310. [CrossRef] 
16. Nizamov, S.; Willig, K.I.; Sednev, M.V.; Belov, V.N.; Hell, S.W. Phosphorylated 3-heteroarylcoumarins and their use in fluorescence microscopy and nanoscopy. Chem. A Eur. J. 2012, 18, 16339-16348. [CrossRef] [PubMed]

17. Sashidhara, K.V.; Kumar, A.; Chatterjee, M.; Rao, K.B.; Singh, S.; Verma, A.K.; Palit, G. Discovery and synthesis of novel 3-phenylcoumarin derivatives as antidepressant agents. Bioorg. Med. Chem. Lett. 2011, 21, 1937-1941. [CrossRef]

18. Matos, M.J.; Terán, C.; Pérez-Castillo, Y.; Uriarte, E.; Santana, L.; Viña, D. Synthesis and Study of a Series of 3-Arylcoumarins as Potent and Selective Monoamine Oxidase B Inhibitors. J. Med. Chem. 2011, 54, 7127-7137. [CrossRef]

19. Pisano, M.B.; Kumar, A.; Medda, R.; Gatto, G.; Pal, R.; Fais, A.; Era, B.; Cosentino, S.; Uriarte, E.; Santana, L.; et al. Antibacterial Activity and Molecular Docking Studies of a Selected Series of Hydroxy-3-arylcoumarins. Molecules 2019, 24, 2815. [CrossRef]

20. Matos, M.J.; Vilar, S.; Kachler, S.; Fonseca, A.; Santana, L.; Uriarte, E.; Borges, F.; Tatonetti, N.P.; Klotz, K.N. Insight into the interactions between novel coumarin derivatives and human A3 adenosine receptors. ChemMedChem 2014, 9, 2245-2253. [CrossRef]

21. Mah, S.; Jang, J.; Song, D.; Shin, Y.; Latif, M.; Jung, Y.; Hong, S. Discovery of fluorescent 3-heteroarylcoumarin derivatives as novel inhibitors of anaplastic lymphoma kinase. Org. Biomol. Chem. 2019, 17, 186-194. [CrossRef]

22. Pintus, F.; Matos, M.J.; Vilar, S.; Hripcsak, G.; Varela, C.; Uriarte, E.; Santana, L.; Borges, F.; Medda, R.; Di Petrillo, A.; et al. New insights into highly potent tyrosinase inhibitors based on 3-heteroarylcoumarins: Anti-melanogenesis and antioxidant activities, and computational molecular modeling studies. Bioorg. Med. Chem. 2017, 25, 1687-1695. [CrossRef] [PubMed]

23. Costas-Lago, M.C.; Besada, P.; Rodríguez-Enríquez, F.; Viña, D.; Vilar, S.; Uriarte, E.; Borges, F.; Terán, C. Synthesis and structure-activity relationship study of novel 3-heteroarylcoumarins based on pyridazine scaffold as selective MAO-B inhibitors. Eur. J. Med. Chem. 2017, 139, 1-11. [CrossRef] [PubMed]

24. Matos, M.J.; Varela, C.; Vilar, S.; Hripcsak, G.; Borges, F.; Santana, L.; Uriarte, E.; Fais, A.; Di Petrillo, A.; Pintus, F.; et al. Design and discovery of tyrosinase inhibitors based on a coumarin scaffold. RSC Adv. 2015, 5, 94227-94235. [CrossRef]

25. Lin, H.-C.; Tsai, S.-H.; Chen, C.-S.; Chang, Y.-C.; Lee, C.-M.; Lai, Z.-Y.; Lin, C.-M. Structure-activity relationship of coumarin derivatives on xanthine oxidase-inhibiting and free radical-scavenging activities. Biochem. Pharmacol. 2008, 75, 1416-1425. [CrossRef] [PubMed]

26. Pramod, A.G.; Renuka, C.G.; Nadaf, Y.F. Electronic Structure, Optical Properties and Quantum Chemical Investigation on Synthesized Coumarin Derivative in Liquid Media for Optoelectronic Devices. J. Fluoresc. 2019, 29, 953-968. [CrossRef] [PubMed]

27. Kohn, W. Nobel Lecture: Electronic structure of matter-Wave functions and density functionals. Rev. Mod. Phys. 1999, 71, 1253-1266. [CrossRef]

28. Azad, I.; Akhter, Y.; Khan, T.; Azad, M.I.; Chandra, S.; Singh, P.; Kumar, D.; Nasibullah, M. Synthesis, quantum chemical study, AIM simulation, in silico ADMET profile analysis, molecular docking and antioxidant activity assessment of aminofuran derivatives. J. Mol. Struct. 2019, 127285. [CrossRef]

29. Molteni, E.; Cappellini, G.; Onida, G.; Mula, G. Extensive stacking of DHI-like monomers as a model of out-of-plane complexity in eumelanin protomolecules: Chemical and structural sensitivity of optical absorption spectra. Chem. Phys. 2019, 524, 92-100. [CrossRef]

30. Zhao, D.; Lu, Q.; Su, R.; Li, Y.; Zhao, M. Light harvesting and optical-electronic properties of two quercitin and rutin natural dyes. Appl. Sci. 2019, 9, 2567. [CrossRef]

31. Marques, M.A.L.; Gross, E.K.U. Time-Dependent Density Functional Theory. Annu. Rev. Phys. Chem. 2004, 55, 427-455. [CrossRef]

32. Basavarajappa, K.V.; Arthoba Nayaka, Y.; Purushothama, H.T.; Vinaya, M.M.; Antony, A.; Poornesh, P. Optoelectronic and current-voltage studies for novel coumarin dyes. Int. J. Environ. Anal. Chem. 2019, 1-14. [CrossRef]

33. Hara, K.; Sato, T.; Katoh, R.; Furube, A.; Ohga, Y.; Shinpo, A.; Suga, S.; Sayama, K.; Sugihara, H.; Arakawa, H. Molecular design of coumarin dyes for efficient dye-sensitized solar cells. J. Phys. Chem. B 2003, 107, 597-606. [CrossRef] 
34. Oprea, C.I.; Panait, P.; Cimpoesu, F.; Ferbinteanu, M.; Girtu, M.A. Density functional theory (DFT) study of coumarin-based dyes adsorbed on $\mathrm{TiO}(2)$ nanoclusters-applications to dye-sensitized solar cells. Materials 2013, 6, 2372-2392. [CrossRef]

35. Hara, K.; Wang, Z.-S.; Sato, T.; Furube, A.; Katoh, R.; Sugihara, H.; Dan-oh, Y.; Kasada, C.; Shinpo, A.; Suga, S. Oligothiophene-containing coumarin dyes for efficient dye-sensitized solar cells. J. Phys. Chem. B 2005, 109, 15476-15482. [CrossRef]

36. Sánchez-de-Armas, R.; San Miguel, M.Á.; Oviedo, J.; Sanz, J.F. Coumarin derivatives for dye sensitized solar cells: A TD-DFT study. Phys. Chem. Chem. Phys. 2012, 14, 225-233. [CrossRef]

37. Mutlak, F.; Mohi, A.; Alwan, T. Density functional theory study of molecular structure, Electronic properties, UV-Vis spectra on coumarin102. Baghdad Sci. J. 2016, 13, 143-152. [CrossRef]

38. Kumar, A.; Cappellini, G.; Delogu, F. Electronic and optical properties of chromophores from hexeneuronic acids. Cellulose 2019, 26, 1489-1501. [CrossRef]

39. Liu, X.; Cole, J.M.; Low, K.S. Solvent Effects on the UV-vis Absorption and Emission of Optoelectronic Coumarins: A Comparison of Three Empirical Solvatochromic Models. J. Phys. Chem. C 2013, 117, 14731-14741. [CrossRef]

40. Pramod, A.G.; Renuka, C.G.; Nadaf, Y.F.; Rajaramakrishna, R. Impact of solvents on energy gap, photophysical, photometric properties for a new class of 4-HCM coumarin derivative: Nonlinear optical studies and optoelectronic applications. J. Mol. Liq. 2019, 292, 111383. [CrossRef]

41. O’Boyle, N.M.; Banck, M.; James, C.A.; Morley, C.; Vandermeersch, T.; Hutchison, G.R. Open Babel: An open chemical toolbox. J. Cheminform. 2011, 3, 33. [CrossRef]

42. Rassolov, V.A.; Ratner, M.A.; Pople, J.A.; Redfern, P.C.; Curtiss, L.A. 6-31G* basis set for third-row atoms. J. Comput. Chem. 2001, 22, 976-984. [CrossRef]

43. Lee, C.; Yang, W.; Parr, R.G. Development of the Colle-Salvetti correlation-energy formula into a functional of the electron density. Phys. Rev. B 1988, 37, 785-789. [CrossRef]

44. Becke, A.D. Density-functional thermochemistry. III. The role of exact exchange. J. Chem. Phys. 1993, 98, 5648-5652. [CrossRef]

45. Stephens, P.J.; Devlin, F.J.; Chabalowski, C.F.; Frisch, M.J. Ab Initio Calculation of Vibrational Absorption and Circular Dichroism Spectra Using Density Functional Force Fields. J. Phys. Chem. 1994, 98, 11623-11627. [CrossRef]

46. Chermette, H. Chemical reactivity indexes in density functional theory. J. Comput. Chem. 1999, 20, 129-154. [CrossRef]

47. Kumar, A.; Gatto, G.; Delogu, F.; Pilia, L. DFT study of $[\mathrm{Pt}(\mathrm{Cl}) 2 \mathrm{~L}]$ complex ( $\mathrm{L}=$ rubeanic acid) and its derived compounds with DNA purine bases. Chem. Phys. 2020, 530, 110646. [CrossRef]

48. Kumar, A.; Cardia, R.; Cappellini, G. Electronic and optical properties of chromophores from bacterial cellulose. Cellulose 2018, 25, 2191-2203. [CrossRef]

49. Cardia, R.; Malloci, G.; Mattoni, A.; Cappellini, G. Effects of TIPS-Functionalization and Perhalogenation on the Electronic, Optical, and Transport Properties of Angular and Compact Dibenzochrysene. J. Phys. Chem. A 2014, 118, 5170-5177. [CrossRef]

50. Jones, R.O.; Gunnarsson, O. The density functional formalism, its applications and prospects. Rev. Mod. Phys. 1989, 61, 689-746. [CrossRef]

51. Malloci, G.; Cappellini, G.; Mulas, G.; Satta, G. Quasiparticle effects and optical absorption in small fullerenelike GaP clusters. Phys. Rev. B 2004, 70, 205429. [CrossRef]

52. Cardia, R.; Malloci, G.; Rignanese, G.M.; Blase, X.; Molteni, E.; Cappellini, G. Electronic and optical properties of hexathiapentacene in the gas and crystal phases. Phys. Rev. B 2016, 93, 235132. [CrossRef]

53. Molteni, E.; Cappellini, G.; Onida, G.; Fratesi, G. Optical properties of organically functionalized silicon surfaces: Uracil-like nucleobases on Si(001). Phys. Rev. B 2017, 95, 075437. [CrossRef]

54. Valiev, M.; Bylaska, E.J.; Govind, N.; Kowalski, K.; Straatsma, T.P.; Van Dam, H.J.J.; Wang, D.; Nieplocha, J.; Apra, E.; Windus, T.L.; et al. NWChem: A comprehensive and scalable open-source solution for large scale molecular simulations. Comput. Phys. Commun. 2010, 181, 1477-1489. [CrossRef]

55. Frisch, M.J.; Trucks, G.W.; Schlegel, H.B.; Scuseria, G.E.; Robb, M.A.; Cheeseman, J.R.; Scalmani, G.; Barone, V.; Petersson, G.A.; Nakatsuji, H.; et al. Gaussian 16 Rev. C.01; Gaussian Inc.: Wallingford, CT, USA, 2016.

56. Thompson, M.A. ArgusLab 4.0.1; Planaria Software LLC: Seattle, WA, USA, 2004. 
57. Wang, J.; Wolf, R.M.; Caldwell, J.W.; Kollman, P.A.; Case, D.A. Development and testing of a general amber force field. J. Comput. Chem. 2004, 25, 1157-1174. [CrossRef]

58. Case, D.A.; Cheatham, T.E.; Darden, T.; Gohlke, H.; Luo, R.; Merz, K.M.; Onufriev, A.; Simmerling, C.; Wang, B.; Woods, R.J. The Amber biomolecular simulation programs. J. Comput. Chem. 2005, 26, 1668-1688. [CrossRef]

59. Kumar, A.; Chakravarty, H.; Bal, N.C.; Balaraju, T.; Jena, N.; Misra, G.; Bal, C.; Pieroni, E.; Periasamy, M.; Sharon, A. Identification of calcium binding sites on calsequestrin 1 and their implications for polymerization. Mol. Biosyst. 2013, 9, 1949-1957. [CrossRef]

60. Kumar, A.; Sechi, L.A.; Caboni, P.; Marrosu, M.G.; Atzori, L.; Pieroni, E. Dynamical insights into the differential characteristics of Mycobacterium avium subsp. paratuberculosis peptide binding to HLA-DRB1 proteins associated with multiple sclerosis. New J. Chem. 2015, 39, 1355-1366. [CrossRef]

61. Phillips, J.C.; Braun, R.; Wang, W.; Gumbart, J.; Tajkhorshid, E.; Villa, E.; Chipot, C.; Skeel, R.D.; Kalé, L.; Schulten, K. Scalable molecular dynamics with NAMD. J. Comput. Chem. 2005, 26, 1781-1802. [CrossRef]

62. Linstrom, P.J.; Mallard, W.G. NIST Chemistry WebBook; National Institute of Standards and Technology: Gaithersburg, MD, USA, 2018; p. 20899.

63. Johnson, R.D., III. NIST Computational Chemistry Comparison and Benchmark Database, Release 20; U.S. Secretary of Commerce: Washington, DC, USA, 2019.

64. Alam, M.; Alam, M.J.; Azaz, S.; Parveen, M.; Park, S.; Ahmad, S. DFT/TD-DFT calculations, spectroscopic characterizations (FTIR, NMR, UV-vis), molecular docking and enzyme inhibition study of 7-benzoyloxycoumarin. Comput. Biol. Chem. 2018, 73, 65-78. [CrossRef]

65. Munshi, P.; Guru Row, T.N. Exploring the Lower Limit in Hydrogen Bonds: Analysis of Weak C-H $\cdots \mathrm{O}$ and $\mathrm{C}-\mathrm{H} \cdots \pi$ Interactions in Substituted Coumarins from Charge Density Analysis. J. Phys. Chem. A 2005, 109, 659-672. [CrossRef]

66. Redchenko, V.V.; Safronov, A.I.; Kirpichenok, M.A.; Grandberg, I.I.; Traven', V.F. Electronic structure of $\pi$-systems. XV. Photoelectron spectra of 7-aminocoumarin derivatives. J. Gen. Chem. USSR 1992, 62, 2313.

67. Bauzá, A.; Quiñonero, D.; Deyà, P.M.; Frontera, A. Is the use of diffuse functions essential for the properly description of noncovalent interactions involving anions? J. Phys. Chem. A 2013, 117, 2651-2655. [CrossRef] [PubMed]

(C) 2019 by the authors. Licensee MDPI, Basel, Switzerland. This article is an open access article distributed under the terms and conditions of the Creative Commons Attribution (CC BY) license (http://creativecommons.org/licenses/by/4.0/). 